\title{
Characterization of Cryptococcus Neoformans Strains From Cases of Cryptococcal Meningitis in India
}

\author{
Harish C. Gugnani, Thomas G. Mitchell, Anubha Paliwal-Joshi, Ashok Rattan
}

\begin{abstract}
Reports of clinical isolates of Cryptococcus neoformans often lack information on their mating types, molecular types, and in vitro antimycotic susceptibilities. This study compares these and other related characteristics of fifteen strains of $C$. neoformans obtained from cases of meningitis in different regions of India. PCR was used to determine the mating type and serotype of each strain, and Amplified Fragment Length Polymorphism (AFLP) was used for molecular typing of the strains. In vitro assays compared the proteinase and phospholipase activities of the strains, and the Clinical and Laboratory Standards Institute (CLSI) protocol was used to determine their minimal inhibitory concentrations (MICs) to amphotericin B (AMB), itraconazole, and fluconazole. All strains were identified as $C$. neoformans var. grubii (serotype A), possessed the alpha mating type, and belonged to molecular type VNII. Ten of the strains demonstrated strong proteolytic activity, and the remaining five were weakly proteolytic. Nine of the strains were positive for phospholipase. In vitro antifungal susceptibility tests, determined the MIC $(\mu \mathrm{g} / \mathrm{ml})$ values for AMB, itraconazole, and fluconazole to be $0.03-0.5,0.002-03$, and $2-4 \mu \mathrm{g} / \mathrm{ml}$, respectively. Remarkedly, all 15 strains belonged to the relatively rare molecular type, VNII. This report is one of few studies to characterize clinical strains of $C$. neoformans from India.
\end{abstract}

Index Terms - Cryptococcus neoformans; meningitis; AIDS patients; India.

\section{INTRODUCTION}

Cryptococcus neoformans, a basidiomycetous encapsulated yeast, is the etiological agent of Cryptococcosis in humans and animals [3], [11]. Out of the five recognized serotypes based on antigenic analysis of the polysaccharide capsule, and comparison of genomic sequences, serotype A (C. neoformans var. grubii) is distributed worldwide in both patients and the environment [9], [11]. Information on the serotypes, molecular types, proteinase and phospholipase activity, and in vitro antifungal susceptibility of Indian strains of $C$. neoformans has been lacking. The present study investigates these aspects of 15 strains of $C$. neoformans originating from cases of meningitis in AIDS patients in India.

Published on July 21, 2020

Harish C. Gugnani, University of Delhi, India.

(corresponding e-mail: harish.gugnani@gmail.com)

Thomas G. Mitchell, Duke University School of Medicine, USA

Anubha Paliwal-Joshi, Indira Gandhi National Open University, India.

Ashok Rattan, Path Kind Labs, India.

\section{MAtERIALS AND MethodS}

\section{A. Identification of strains}

Fifteen strains referred to us originated from cases of meningitis in different parts of India. Diagnosis of meningitis was based on demonstration of encapsulated yeast cells in India ink preparations and positive fungal culture, and in some cases, detection of capsular polysaccharide in the samples of cerebrospinal fluid (CSF). Identification of the purified cultures as $C$. neoformans was based on the demonstration of capsule in India ink mounts, formation of dark brown colonies on Niger seed agar (positive phenol oxidase test), esculin agar, and L-DOPA medium, hydrolysis of urea, growth at $37^{\circ} \mathrm{C}$, carbohydrate assimilation tests as determined by Vitek 2 Yeast ID system (bioMerieux, Marcy-l'Étoile, France), and evidence of minimal growth with no color change from yellow-green to cobalt blue on Canavanine-Glycine- Bromothymol Blue (CGB) medium (Hardy Diagnostics, Santa Maria, USA).

\section{B. Determination of mating type and serotype}

The mating type and serotype of each strain was determined using a touchdown PCR method [6]. The primers for mating type and serotype analyses were JOHE1909 /JOHE1910 (MF2 $\alpha$ D), JOHE 3067 / JOHE 3068 (STE 20a D), JOHE 3069 / JOHE 3070 (STE 20 $\alpha$ D), JOHE 1895 / JOHE 1896 (STE 11 $\alpha$ D), JOHE 1671/ JOHE 1672 (STA $12 \alpha$ A+D), JOHE $1671 / 2189$ (STA 12 $\alpha$ A), JOHE 3065 / JOHE 3066 (CLA4 D), JOHE 3066 / 3236 (CLA4 D), JOHE 2926 / JOHE 3238 (CAN1 D), JOHE 2926 / JOHE 3239 (CAN1 A), JOHE 2596 / JOHE 3240 (GPA1 D), JOHE 2596 / JOHE 3241 (GPA1AD). Primer sequences were as listed in an earlier study [15]. PCRs for mating type and serotype were repeated twice. Serotyping of the strains was also done by Crypto Check kit (Iatron Laboratories Inc., Tokyo, Japan) as per the manufacturer's instructions.

\section{Molecular typing}

To determine the molecular type(s) of the strains of $C$. neoformans var. grubii, we used a robust Amplified fragment length polymorphism (AFLP) method, generating markers using two different restriction enzymes and primer extensions, as previously described [17].

\section{Proteinase and phospholipase activity of the strains}

Proteinase activity of the strains was tested with $0.4 \%$ albumin as substrate as per the method described earlier [21] with minor modifications [4]. The phospholipase activity was determined by the procedure described earlier [19] using the egg-yolk plate method of Price et al. [20]. The 
diameter of the colony (a) and that of the colony plus precipitation zone (b) of the test isolate were measured after 7 days of incubation of triplicate inoculated egg-yolk plates. The phospholipase activity was expressed as mean $\mathrm{Pz}=\mathrm{a} / \mathrm{b}$. Thus, a high PZ value reflects low production of phospholipase.

\section{E. In vitro antifungal susceptibility tests}

The in vitro activity of the antifungal agents was determined by micro-broth dilution technique as described in the M27-A protocol of the Clinical and Laboratory Standards Institute (CLSI) with RPMI 1640 broth buffered to $\mathrm{pH} 7$ using MOPS (Sigma). The MICs were determined as the lowest concentration that substantially inhibited the growth of the test isolate. Reference strains Candida albicans ATCC 90028 and Candida parapsilosis ATCC 22 019 were used for quality control.

\section{Results AND Discussion}

All the strains utilized, cellobiose, galactose, glucose, erythritol inositol, maltose, mannitol, melezitose, D-Methyl glucoside, raffinose, rhamnose, salicin, soluble starch, sorbose, sucrose, trehalose, D-xylose, but did not utilize lactose, melibiose. The isolates grew well at $37{ }^{\circ} \mathrm{C}$, hydrolyzed urea but did not utilize nitrate as a source of nitrogen and were sensitive to cycloheximide $\left(0.4 \mathrm{mg} \mathrm{mL}^{-1}\right)$. PCR and testing with Crypto-check indicated that all isolates were serotype A. All the isolates belonged to alpha mating type by PCR analysis, and molecular type VNII as determined by AFLP. Eleven of the isolates were strongly positive for proteinase, while four exhibited weak proteolytic activity. Nine of the isolates were positive for phospholipase $\mathrm{x}(\mathrm{Pz}$ value 0.03 to 0.045$)$. In vitro susceptibility tests determined the MIC $(\mu \mathrm{g} / \mathrm{ml})$ values for amphotericin $\mathrm{B}$, itraconazole, and fluconazole were 0.03 $0.5,0.02-03$, and $2-4 \mu \mathrm{g} / \mathrm{ml}$, respectively

Cryptococcus neoformans is traditionally classified into three varieties with five serotypes: var. grubii (serotype A), var. neoformans (serotype D), var. gattii (serotypes B and C) and serotype AD (hybrid of serotypes A and D). Serotype A (C. neoformans var. grubii) is the predominant serotype amongst the strains from AIDS patients worldwide. The data on the serotype and molecular type distribution of Indian isolates of Cryptococcus neoformans has been lacking. In an analysis of 36 North Indian isolates [2], most of them, i.e., $31(87 \%)$ were found to belong to serotype A (var. grubii)). All 15 of our strains possessed the MAT- alpha mating type as tested by PCR analysis and with Crypto-Check. It may be mentioned here that two isolates of $C$. neoformans recovered from the bark of Eucalyptus camaldulensis in India were also found to belong to MAT- alpha mating type and serotype A (var. grubii)) [10]. The MIC values of our strains of $C$. neoformans for the three antimycotics agreed closely with the results of a Brazilian study of clinical isolates of $C$. neoformans [8] and a similar Indian study [7]. The MIC values of our isolates for amphotericin $\mathrm{B}$ and itraconazole also closely agreed with the results of a study on environmental isolates of $C$. neoformans from India [13]; however, the MIC values of our isolates for fluconazole are much higher $(2-4 \mathrm{ug} / \mathrm{ml})$ than reported by these authors. The extracellular enzymes of $C$. neoformans, proteinase and phospholipase, are regarded as important virulent factors [1]. It is noteworthy that nine of the fifteen isolates exhibited marked activity for both of these enzymes. Five molecular types can be distinguished within the $C$. neoformans species complex: VNI, VNII, and VNB (C. neoformans var. grubii), VNIV (C. neoformans var. neoformans), and the intervarietal hybrids identified by molecular type VNIII [18]. Molecular types of $C$. neoformans may vary in different geographic locales. Molecular type VNII has been isolated from all the continents, although less frequently. However, the prevalence of molecular type VNII is probably underestimated. A review of global molecular epidemiology of Cryptococcus neoformans showed that the type VNII is rare though reported from several countries [6]. Very recently several isolates of molecular type VNII have been identified from environmental sources in Nigeria [18], environmental and clinical sources in Libya, and clinical sources in Madagascar and Italy [5].

\section{CONCLUSION}

A remarkable finding is that all the 15 strains belonged to the relatively rare molecular type, VNII. This study provides useful data on characteristics of strains of $C$. neoformans from India.

\section{ACKNOWLEDGMENT}

The senior author is grateful to Dr. Aruna Sahani, Amrita Institute of Medical Sciences and Research Centre Ponekkara, P. O. Kochi, Kerala, and Prof Arora at Government Medical College, Amritsar, Punjab, for sending their strains of Cryptococcus neoformans for confirmation of their identity and for our further study.

\section{CONFLICT OF INTEREST}

The authors declared no potential conflicts of the interest with respect to the research, authorship, and or publication of this article.

\section{REFERENCES}

1. Almeida F, Wolf JM, Casadevall A. Virulence-associated enzymes of Cryptococcus neoformans. Eukaryot Cell 2015;14(12):1173-85.

2. Banerjee U, Datta K, Casadevall A. Serotype distribution of Cryptococcus neoformans in patients in a tertiary care center in India. Med Mycol 2004;42(2):181-6.

3. Casadevall A, Perfect JR Cryptococcus neoformans. Washington DC: American Society for Microbiology Press, 1998.

4. Chakrabarti, A, Nayak N, Talwar P. In vitro proteinase production by Candida species. Mycopathologia 1991;114(3):163-8.

5. Cogliati M. Global Molecular epidemiology of Cryptococcus neoformans and Cryptococcus gattii: an atlas of the molecular types. Scientifica 2013; DOI: $\underline{10.1155 / 2013 / 675213}$

6. Cogliati M, Andrianarivelo MR, Ellabib M, Nandi EN, Cornet M. Molecular-type specific multiplex PCR produces a distinct VNII PCR pattern among Cryptococcus neoformans species complex. Med Mycol 2019;57(3):384-86.

7. Datta K, Jain, Sethi S, Rattan A, Casadevall A, Banerjee U. Fluconazole and itraconazole susceptibility of clinical isolates of Cryptococcus neoformans at a tertiary care center in India: a need for care. J Antimicrobial Chemotherap 2003;52(4):683-6.

8. Favalessa OC, DAJ de Paulautra V, Nakazalo L, Tadna T, Lazera MD, Wanke B. et al. Molecular typing and in vitro antifungal susceptibility 
of Cryptococcus spp from patients in Midwest Brazil. J Infect Dev Ctries 2014;8(8):1037-43.

9. Franzot SP, Salkin IF, Casadevall A. Cryptococcus neoformans var. grubii: separate varietal status for Cryptococcus neoformans serotype A isolates. J Clin Microbiol 1999;37(2):838-40.

10. Gugnani HC, Mitchell TG, Litvintseva AP, Lengeler K Heitman J. Kumar A, Basu S and Paliwal-Joshi A. Isolation of Cryptococcus gattii and C. neoformans var. grubii from the flowers and bark of Eucalyptus trees in India. Medical Mycology 2005(6);43(6):565-9.

11. Heitman J, Kozel T, Kwon-Chung KJ et al. Eds. Cryptococcus: from human pathogenic model Yeast. Washington, DC, USA: American Society for Microbiology Press, 2010.

12. Ito-Kuwa S, NaKamura K, Aoki S, Vidotto V. Serotype identification of Cryptococcus neoformans by multiplex PCR. Mycoses 2007;50(4):277-81.

13. Khan ZU, Randhawa HS, Kowshik t, Chowdhary A, Chandy R. Antifungal susceptibility of Cryptococcus neoformans and Cryptococcus gattii isolates from decayed wood of trunk hollows of Ficus religiosa and Syzygium cumini trees in northwestern India. J Antimicrobial Chemotherap 2007;60(2):312-6.

14. Kurtzman P, Fell JW Eds The yeasts - A Taxonomic Study $4^{\text {th }}$ Edition, Amsterdam, Elsevier, 1998

15. Lengeler KB, Wang P, Cox GM, Perfect JR, Heitman J. Identification of the MATa mating-type locus of Cryptococcus neoformans reveals a serotype A MATa strain thought to have become extinct. Proc Natl Acad Sci USA2000 Dec 19;97(26):14455-60.doi: 10.1073/pnas.97.265.

16. Lengeler KL, Cox GM, Heitman J. Serotype AD strains of Cryptococcus neoformans are diploid or aneuploid and are heterozygous at 14 mating type locus. Infect Immun 2001:69(1):11522.

17. Litvintseva AP, Marra RE, Nielsen K, Heitman J, Vilgalys RJ, Mitchell TG. Evidence of sexual recombination among Cryptococcus neoformans serotype A isolates in sub-Saharan Africa. Eukaryotic Cell 2003;2(6):1162-68

18. Nnadi NE, Enweani IB, Cogliati M, Ayanbimpe GM, Okolo MO, Kim E, Sabitu MZ, Criseo G, Romeo O, Scordino F. Molecular characterization of environmental Cryptococcus neoformans VNII isolates in Jos, Plateau State, Nigeria. J Med Mycol 2016 26(4): 30611.

19. Polak A. Virulence of Candida albicans mutants. Mycoses 1991;35(1-2):9-16.

20. Price MF, Wilkinson ID, Gentry LO. Plate method for detection of phospholipase activity of Candida albicans. Sabouraudia 1998;20(1):714.

21. Ruchel, R., R. Tegeler, M.A Trost. A. comparison of secretory proteases from different strains of Candida albicans. Sabouraudia $1982 ; 20(3): 233-34$

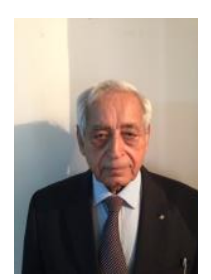

Harish C Gugnani: 10th April 1938. Place of birth: Lyallpur, India.

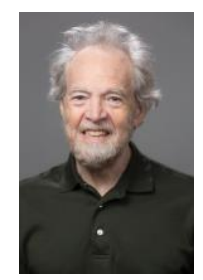

Thomas G Mitchell: 31st March, 1941. Place of birth: New York, USA.

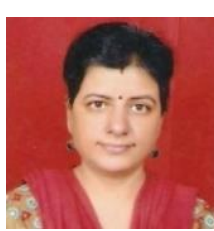

Dr Anubha Joshi: 29th OCtober 1968 Place of birth: Delhi, India.

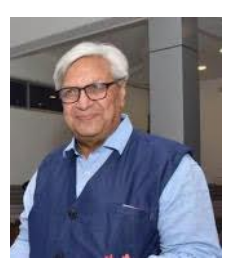

Ashok Rattan: 14th December 1952 Place of birth: New Delhi, India. 